Chirurgia (2017) 112: 418-428

No. $4, \quad$ July - August

Copyright@ Celsius

http://dx.doi.org/10.21614/chirurgia.112.4.418

\title{
Review on Practical Approach in Multiple Breast Carcinomas: Does Each Focus Matter?
}

\author{
Monica Boros', Rares Georgescu' ${ }^{2}$ Cristian Podoleanu ${ }^{3}$, Simona Stolnicu ${ }^{4}$ \\ 'Department of Pathology, County Emergency Clinical Hospital, Oradea, Romania \\ 2Department of Surgery, University of Medicine and Pharmacy Tirgu Mures, Tirgu Mures, Romania \\ ${ }^{3}$ Department of Cardiology, University of Medicine and Pharmacy Tirgu Mures, Tirgu Mures, Romania \\ ${ }^{4}$ Department of Pathology, University of Medicine and Pharmacy Tirgu Mures, Tirgu Mures, Romania
}

Corresponding author:

Cristian Podoleanu, MD

Department of Cardiology,

University of Medicine

and Pharmacy Tirgu Mures

Gh. Marinescu street, no. 1

540099, Tirgu Mures, Romania

E-mail: podoleanu@me.com

\section{Rezumat}

Reevaluarea unei abordări practice în carcinoamele mamare multiple: cât de mult contează fiecare focar tumoral?

Carcinomul mamar reprezintă cea mai frecventă tumoră malignă ce se dezvoltă la sexul feminin. De obicei, este o tumoră unică dar, uneori, poate fi multiplă. Datele din literatură cu privire la incidența, definiția, profilul morfologic şi molecular, tratamentul şi prognosticul carcinoamelor mamare multiple sunt contradictorii, de aceea, acest articol prezintă o abordare practică pentru cei implicați în diagnosticul şi tratamentul unei astfel de leziuni care, poate prezenta heterogeneitate morfologică şi moleculară, acest lucru având un impact asupra managementului şi prognosticului. De aceea, este esential ca focarele tumorale multiple să se raporteze separat şi să fie luate în considerare în momentul unei decizii terapeutice.

Cuvinte cheie: focare tumorale multiple, carcinom mamar

\section{Abstract}

Breast carcinoma is the most frequent form of cancer encountered in women worldwide. In the routine practice, most of breast carcinomas are diagnosed as unifocal, however, a variable proportion is represented by multiple tumor foci. Since data regarding the incidence, definition, morphological and molecular profile, treatment and 
prognosis of multiple breast carcinomas are currently contradictory we are presenting a practical approach for pathologists dealing with such a lesion, which may display morphological and molecular heterogeneity among multiple foci with an impact on management and prognosis. Multiple tumor foci should be reported separately and taken into account when establishing the treatment.

Key words: multiple tumor foci, breast carcinoma

\section{Introduction}

Breast carcinoma is the most frequent form of cancer encountered in women worldwide, as it represents $23 \%$ of all cancers globally, with 1.38 million newly diagnosed cases/year, and $28 \%$ of all forms of cancer in Europe (1). In Romania, breast cancer is a major public health issue as the incidence of breast cancer increased steadily during the last decades in Romania, from 25/100.000 women in 1988 to $61.1 / 100.000$ in 2008 (2).

In the routine practice, most of breast carcinomas are diagnosed as unifocal, while a variable proportion is represented by multiple tumors. Data available in the literature regarding the incidence, definition, morphological and molecular profile, treatment and prognosis of multiple carcinomas are currently contradictory and insufficient for best patient management. We are presenting here a practical approach for pathologist dealing with breast cancer diagnosis and management, based on the review of international literature and several studies that we have performed and published on this topic aiming to demonstrate that each focus of multiple breast carcinoma matters.

\section{Incidence}

The incidence of multiple breast carcinomas varies in the English medical literature between 6.1 and $77 \%$, due to differences in definition, inclusion/selection criteria, preoperative diagnostic methods (the incidence is $15 \%$ when detected with mammographic examination and $35 \%$ when detected with MRI and ultrasound) and, last but not least, differences in sampling methods and their correlation with preoperative radiologic examinations used in different onco- logic hospitals $(3,4)$. The incidence of multiple breast carcinoma detection has grown in the last decades with the advent and universal use of preoperative imaging diagnostic methods (mammography, ultrasound and MRI). However, even the use of these imaging methods does not guarantee the discovery of all tumor foci, as some of them are detected only following macroscopic and/or microscopic examination during breast specimen sampling. More recent studies that histopathologically analyzed consecutive cases using the "wide section" method have revealed the presence of multiple, secondary foci in most breast carcinoma patients (5).

Since the data regarding the incidence of multiple breast carcinomas in Romania were missing in English literature, we performed a retrospective study including 1787 consecutive cases diagnosed with breast carcinoma in the Pathology Department of Tîrgu Mures (20022012). We determined the global incidence of multiplicity in breast carcinomas and compared the incidence of multiple carcinomas in 20022006 (when the "traditional" breast specimen sampling method was used) with the incidence in 2007-2012 (after we implemented the new sampling method, also named the "multidisciplinary" method, which correlates radiologic and histological appearances) (6). The global incidence of multifocality in our Pathology Department was $22.55 \%$ (403/1787 cases). The incidence of multiple breast carcinomas increased significantly between 2007-2012 compared to $2002-2006$ (31.04\% versus $13.31 \%$ ) $(p<0.0001)$, starting with the introduction of the concepts of radiologic appearance-correlated sampling and multidisciplinary team and it is similar to data reported in the international medical literature (6). 


\section{Definition and Terminology}

Multiplicity (multifocality/multicentricity) in breast carcinomas is a controversial subject in the literature, as there is no international consensus on the definition. The first author who referred to the presence of multiple breast tumors was John Hunter, in 1839, in "Lectures on the Principles of Surgery", where he suggested the possibility that the multifocality of breast carcinoma originated in multiple foci within the same breast that were rarely detected simultaneously (7). Since then, various definitions have been applied to report these tumors, but the clinical significance by using different definitions is still unknown $(3,8-17)$.

Traditionally, multiple carcinomas have been classified in two categories: multifocal (MF) and multicentric (MC). These definitions were not applied in a uniform manner and these two terms are sometimes used together, which can lead to confusion. Also, the distinction between $\mathrm{MF}$ and $\mathrm{MC}$ carcinomas was made using several criteria: topographic (MF: tumor foci located in the same quadrant /MC: in different quadrants) (3,17-19); histological pattern (similar: MF/different: MC) (20,21); tumor origin - Vlastos and Middleton defined MF tumors as multiple foci of the same tumor, whereas MC involved multiple foci of origin (11,22). A delimitation between MF and MC carcinomas was also attempted by using an arbitrary distance between tumor foci, for instance: $<2 \mathrm{~cm}(\mathrm{MF})$ or $>2 \mathrm{~cm}$ (MC) $(9,23)$; $>3$ cm (MC) (10); <4 cm (MF) and >4 cm (MC) (3); $<5 \mathrm{~cm}(\mathrm{MF})$ and $>5 \mathrm{~cm}$ (MC) $(8,17,18)$. In order to consider a tumor as MF, some authors recommend a minimum distance between foci: $>1 \mathrm{~mm}$ (24), $>4 \mathrm{~mm}(25,26),>5 \mathrm{~mm}(27,28)$. Some of these authors included both (in situ and invasive carcinomas) in their definitions, others only included invasive carcinomas. Most of these authors only took into account grossly visible foci and ignored microscopic foci. Other authors $(12,13,14,29)$ used both terms together, without making a difference between MF and MC by avoiding "quantitative" delimitations. They considered breast carcinomas to be multiple when multiple invasive foci separated by benign breast tissue are seen, regardless of the distance between foci; topographic criteria and distance between tumor foci are considered by these authors to be parameters of debatable biological significance (5). This definition suggests that according to more recent studies, the morphology and molecular profile of multiple tumor foci are more important parameters to determine the prognosis than is the location or the distance between multiple foci within the breast.

\section{Origin}

As far as their origin is concerned, the development of multiple foci in breast carcinoma could be explained by two mechanisms: these foci may develop as multiple independent tumors, in which case tumors could display different molecular and phenotypic features (polyclonal), or by intramammary dissemination of a single tumor, which would render them identical (monoclonal) (30). Establishing the origin of the multiple breast carcinomas, as well as carrying out clonality studies, are important due to their therapeutic perspectives. However, we have to keep in mind that sometimes multiple independent tumors may have similar morphological and molecular profile within different foci and on the other hand that multiple tumors with identical profile may change in time and differentiate into clones with different profiling especially when metastasizing.

\section{Sampling Method and Pathology Report}

There are two sampling methods which are generally used in diagnosing multiple breast carcinomas: 1 . the randomized biopsy of each breast quadrant not involved by the tumor, along with sampling the principal tumor, which is histologically examined $(15,18,31,32)$ and 2 . the serial gross section method in which the entire breast tissue is examined, allowing a more precise determination of the relationships between lesions, with or without radiologic examination $(5,8,9,21,33)$. The incidence of multiple tumors when using the serial 
section method varies between $21 \%$ and $63 \%$, with a mean value of $43 \%$, while when using randomized quadrant biopsy, the incidence of multifocality varies between $11 \%$ and $41.6 \%$ (with a mean value of 26\%) (25). On the other hand, MD Anderson Cancer Center (USA), uses a more complex method in detecting multiple breast carcinomas, consisting of a correlation between preoperative radiologic appearance and radiographic re-examination of the serial sections performed during sampling, with findings of the gross examination and a very detailed sampling of all suspected tumor (34). This method is, however, extremely costly, as it requires the presence of the radiologist, surgeon, and pathologist during surgery, highly trained personnel and sampling a high number of tissue fragments. In the Pathology Department of Tîrgu Mureş, we adopted the MD Anderson method in 2007. Moreover, a detailed mapping of each sampled focus is performed in each case in order to allow the pathologist to better define, localize, and correlate the presence of multiple tumor foci. (Fig. 1)

The latest editions of AJCC and TNM system define ipsilateral synchronous multiple breast carcinomas as the presence of at least two invasive tumor foci located within the same breast, macroscopically distinct, and assessable using clinical and pathological methods $(35,36)$. The multiple foci should only be assessed in terms of their number, which should be reported between parentheses in the final pathology report. Also, according to the above-mentioned international guidelines, these criteria did not apply to tumors with a single macroscopic focus associated with several separate microscopic foci, which are called "satellite tumors" $(35,36)$. These guidelines recommend the use of the maximum diameter of the largest tumor focus in multiple carcinomas, rather than the sum of all diameters when reporting the tumor in the final pathological report. In a study published in 2016, we aimed to determine the optimal method for tumor size assessment in multiple breast carcinomas, correlated with the development of axillary lymph node metastases. (Fig. 2)

By using the aggregate diameter method, some of the patients enrolled in this study were upstaged to a higher $\mathrm{T}$ stage, but this method of assessing tumor diameter does not correlate with a higher rate of axillary metastases and should not therefore be used in the TNM staging of multiple breast carcinomas (37). The diameter of each tumor foci should

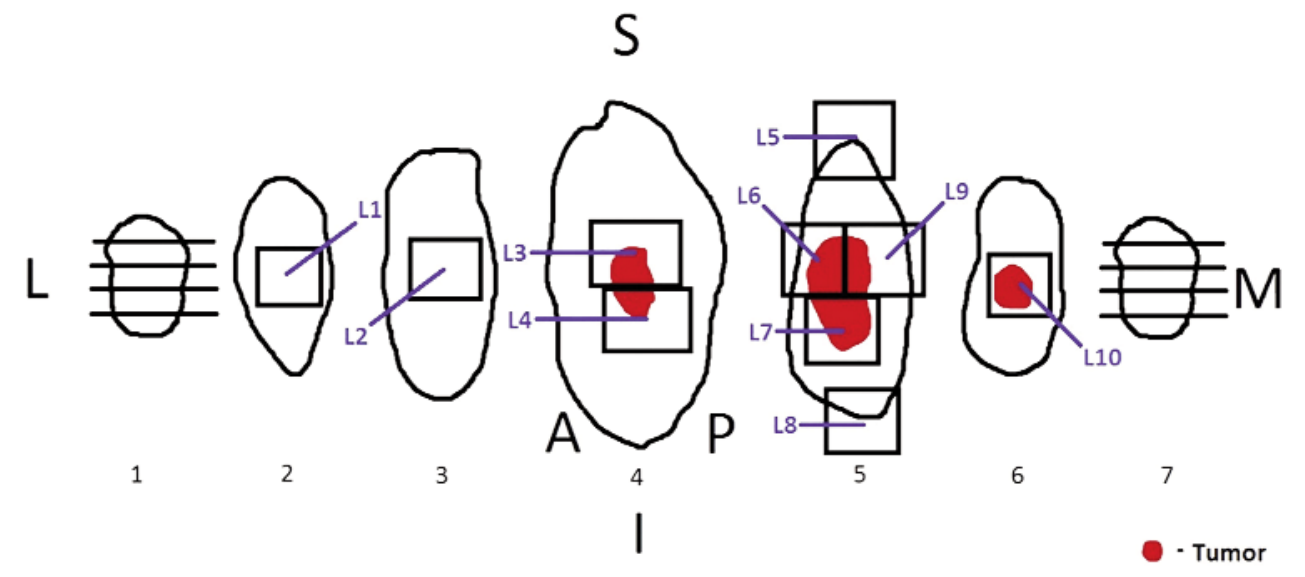

Figure 1. The "map" of the sampled sections filled in by the pathologist; the significance of the each sampled fragment and each microscopic section, following a preexistent code; e.g.: L2 (slide 2)= breast tumor adjacent to the tumor; $L 3, L 4, L 10=$ tumor; $L 5=$ superior resection margin; $L 6=$ Tumor + lateral resection margin; $L 9=$ Tumor+ medial resection margin; L8= inferior resection margin 


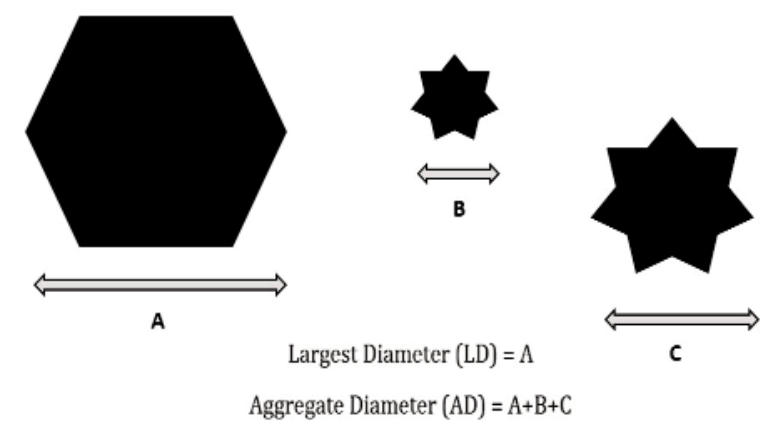

Figure 2. The size of tumor foci in multiple breast carcinomas assessed by using two methods: (1) Largest diameter of the largest tumor focus (LD); (2) Aggregated diameter of all tumor foci appearing in one specimen $(A D)=$ the sum of the maximum diameters of all individual tumor foci

be included in the pathology report, however, since it gives the oncologist an idea about the total volume of the tumor that should be treated; on the other hand, when staging, the largest diameter of the tumor foci should be used.

\section{Morphological Profile}

Multiple foci tumor can be, according to some studies, different from a microscopic standpoint $(22,38,39)$ and polyclonal $(40)$, but other studies state the contrary and uphold the monoclonal theory, according to which these foci are in most cases morphologically identical (22). (Table 1)

The morphological features (histological tumor type and grade) play an important role in deciding the best adjuvant treatment together with the molecular profile. Also, these morpho- logical parameters are involved in assessing the prognosis and risk of relapses. The European Guideline for quality assurance in breast cancer screening and diagnosis (2006) only reports the features of the main tumor (41). According to the AJCC/UICC TNM system's latest edition, the College of American Pathologists (2009) and the ESMO guidelines, only the largest tumor focus should be selected for classification, grading, and staging $(35,36,42,43)$. Clinical decisions in systemic adjuvant therapy for breast cancer are presently based on morphological criteria of the largest tumor focus, ignoring those of the smaller simultaneous cancers even though the heterogeneity of individual foci in multiple carcinomas has not been widely studied (44-46).

In a recently published study, we aimed to assess whether the morphological appearance (i.e. histological tumor type and histological grade) of simultaneous invasive breast carcinoma foci is different, since it is known that adjuvant therapy is established according to these parameters (47). We carried out a retrospective study comprising 498 consecutive patients admitted to our institution, diagnosed with breast carcinoma and surgically treated between 2007-2009 out of which 91 (21.77\%) had multiple invasive tumor foci. In multiple tumors, each lesion was analyzed separately by two authors of this paper (SS and MB). In all cases defined as multiple tumors, we were able to detect an index, principal tumor with the largest diameter of all foci, and additional foci (which always had a smaller size). The histological tumor type of the additional foci was different from the index tumor in $12.08 \%$ of the cases. In 9 cases $(9.89 \%)$ we encountered a

Table 1. Studies analyzing discordance in histological types and grades between multiple tumor foci in invasive multiple breast carcinomas

\begin{tabular}{lccc}
\hline Authors & $\begin{array}{c}\text { No. of cases } \\
\text { analyzed }\end{array}$ & $\begin{array}{c}\text { Proportion of cases with different } \\
\text { histological types (\%) }\end{array}$ & $\begin{array}{c}\text { Proportion of cases with different } \\
\text { microscopic grade (\%) }\end{array}$ \\
\hline Egan et al. (20) & 118 & 25 & Unknown \\
\hline Dawson et al. (30) & 24 & 37.5 & Unknown \\
\hline Andea et al. (38) & 101 & 15.8 & 4.9 \\
\hline Middleton et al. (22) & 32 & 3 & 0 (zero) \\
\hline Moutafoff et al. (39) & 234 & 9 & Unknown \\
\hline Choi et al. (28) & 65 & 37 (histological pattern) & 12 \\
\hline
\end{tabular}


different histological grade compared to the index tumor. Multiple breast carcinomas may show pathological heterogeneity among foci. Tumors with histological types bearing a favorable prognosis and lower histological grades have been encountered in association with simultaneous foci with poorer prognosis and higher histological grade. By reporting only the features of the main tumor, the chances of the patient to receive adjuvant therapy could be diminished (47). By following the international recommendations $(35,36,41)$, at least 8 cases from our study (with only the index tumor previously reported) would have been undertreated (47). We believe that reporting the morphology (histological type and grade) of each tumor focus is imperative.

\section{Molecular Profile}

International therapeutic guides recommend adjuvant endocrine therapy (Tamoxifen) in patients with breast carcinoma in which the tumor expresses estrogen receptors (ERs) and/or progesterone receptors (PRs), as well as anti-human epidermal growth factor receptor 2 (HER2) therapy (Trastuzumab) in HER2positive cases $(43,44,45,48)$. An increased proliferative index (Ki-67), a high histological grade, and ER/PR negativity are factors that indicate the use of chemotherapy $(43,46)$. The assessment of these markers is thus important, because it provides data that are helpful in establishing the treatment and prognosis of breast carcinomas. TNM 2012, AJCC 2010 and CAP guidelines recommend that in multiple tumors, biological parameters (ER, PR, Ki-67, HER2) should only assessed in the largest tumor focus, whereas additional tumor foci are only reported and assessed when they differ morphologically from the main tumor $(35,36$, 42). There are no current international standards regarding work protocols in these multiple carcinomas. However, not enough attention has been paid in the literature to the heterogeneity of multiple carcinoma foci. There are few studies that assessed histological and immunohistochemical features of tumor foci in multiple carcinomas, with contradictory results and variable conclusions $(22,28,30,49,50,51)$. (Table 2)

We aimed at analyzing all tumor foci from an immunohistochemical standpoint and at highlighting concordances or mismatches between them on a series of 806 cases (out of which 155 were multiple tumors) consecutively diagnosed with breast carcinoma between 2007-2012 in Tîrgu Mureş. In our study, we found mismatches in $11.61 \%$ to $29.03 \%$ of cases, depending on the analyzed biological parameter (52). Of the 155 cases analyzed, 61 $(39.35 \%)$ were morphologically and immunophenotypically concordant. Of the 23 cases (14.83\%) in which the multiple foci were

Table 2. Studies summarizing and comparing the immunohistochemical (IHC) profile of multiple breast cancers

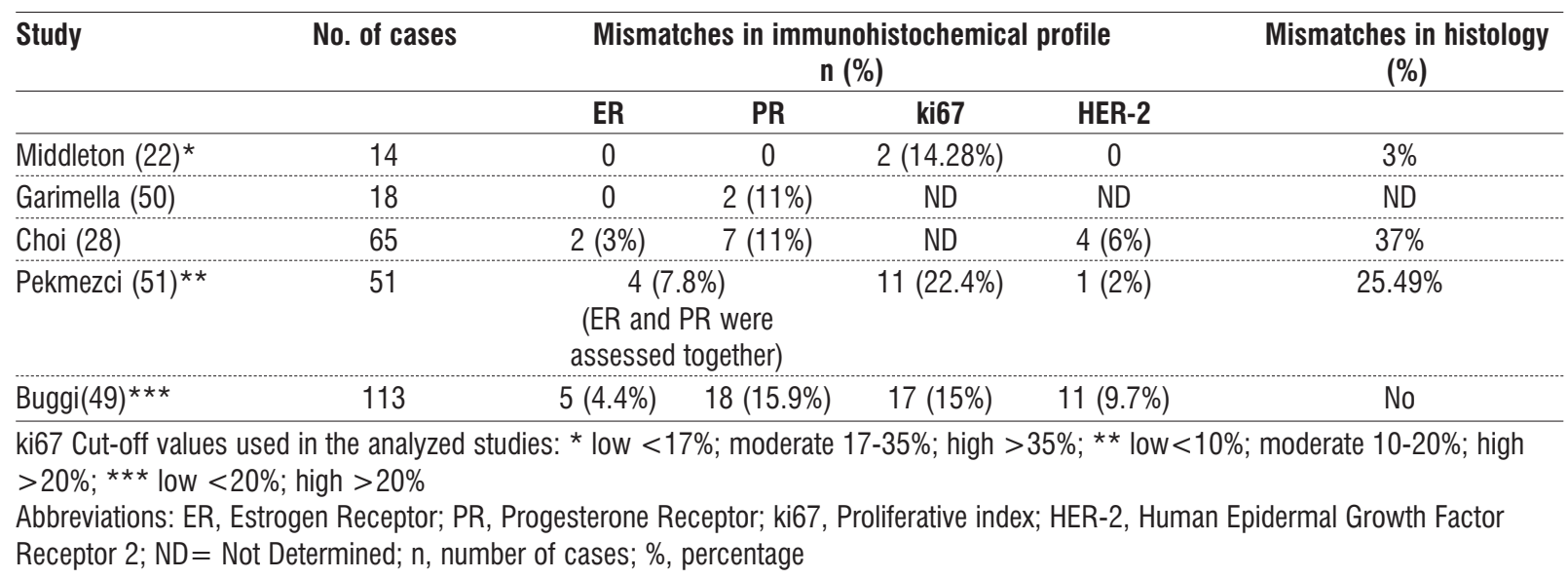


morphologically different, in 10 cases (6.45\%), the foci were immunohistochemically similar but were different in 13 (8.38\%). In 71 cases (45.8\%), although the multiple foci were morphologically identical, there were immunohistochemical mismatches. Our study thus underlines the importance of independently assessing and reporting each tumor focus in multiple carcinomas, morphological features not with standing.

Comparison between primary tumor and axillary lymph nodes regarding morphology and molecular profile

We and other authors have demonstrated that multiple breast carcinomas can differ among foci regarding histology and molecular profile $(28,49,53)$. No studies however analyzing the impact of this heterogeneity on axillary metastases have been performed in multiple breast carcinomas. For this goal, we have recently performed a study on 806 consecutive breast carcinoma cases out of which 155 were multiple tumors. Out of the 155 multiple carcinomas, 115 cases displayed identical histological type and grade in all foci, while 40 cases showed morphological heterogeneity; of these, 11 showed mismatches only between the histological type of the multiple tumor foci, 16 showed mismatches only between histological grade and 13 cases presented with mismatches between both histological type and grade (54).

Out of the cases in which only grade mismatches appeared (but which had the same histological type) and which determined axillary lymph node metastases (14 out of 16 cases), the metastases had the same histology as the multiple breast tumors. The histological grade of the metastases was identical to that of the highest-grade tumor in all cases. In $35.72 \%$ ( 5 of 14 cases), the grade of the metastases was identical to the grade of a smaller tumor than the index tumor. As far as the cases in which only histological type mismatches appeared (but which had identical grades) and which had axillary lymph node metastases (8/11 cases), the histological type of the metastases was homogenous in 4 cases (regardless of the number of metastases), but in the other 4 cases the histological type was heterogeneous (54).

The histological features of axillary lymph node metastases in multiple breast carcinomas correspond to the histological type with unfavorable prognosis and/or highest histological grade, which is not necessarily of the largest tumor focus (54).

Regarding the molecular profile, previous data revealed the instability of the tumor cell proliferation index throughout the metastatic process, which could have clinical consequences and can result in therapeutic changes. Also, comparing the ER, PR, and HER2 status in the primary tumor and paired lymph node metastases, several studies found a variable rate of instability (55-58).

We also aimed to demonstrate that in breast carcinomas the tumor profile is not stable during the metastatic process, with impact on therapeutic decisions. In a recently published paper, we analyzed ER, PR, HER2 status and Ki67 index in 41 primary unifocal (PU) and 37 primary multiple (PM) breast carcinomas with identical immunohistochemical profile among multiple tumor foci and the matched axillary lymph node metastases (59). We excluded from this study cases of multiple breast carcinomas in which the tumor foci were molecular heterogeneous (because we expect these tumors to be associated with heterogeneous lymph node metastases from a molecular point of view). We defined concordant cases those in which the primary tumor (PU or PM) and lymph node metastases displayed identical positivity or negativity for ER, PR, HER2, Ki67 and discordant cases in which there was a mismatch in at least one biological parameter between PU and PM tumor and lymph node metastases. Also, we defined concordant cases those in which the molecular profile (based on the immunohistochemical evaluation of the ER, PR, HER 2, Ki67) was concordant between PU and PM tumor and lymph node metastases, and mismatch cases those in which the molecular profile of the primary tumor differed from the one of the lymph node metastases in at least one lymph node. The positivity for the biological markers is not stable during the metastatic 
process, in this study the total rate of discordant cases was $92.7 \%$ in PU tumors and $75.7 \%$ in PM homogeneous tumors $(\mathrm{p}=0.058, \mathrm{OR}=0.245$, $95 \% \mathrm{CI}=0.06-0.991)$. The total rate of shifted case was $64.9 \%$ in PM tumors and $82.9 \%$ in PU tumors. The highest rate of shifting was encountered from Luminal B-like to Luminal A-like. In 11 out of $37(29.7 \%) \mathrm{PM}$, and in 17 out of 41 (41.5\%) PU cases the subtype shifted to a poorer one regarding prognosis (59). In conclusion, the patients in whom the primary tumor is hormone receptors negative and/or HER2 negative but positive for these markers in the axillary lymph nodes could become eligible for hormonal treatment and/or trastuzumab treatment which may significantly improve the patient's outcome. This is the reason why performing the molecular profile is mandatory in both primary tumor and lymph node metastasis on Tru-cut biopsy specimens at the moment of diagnosis and before establishing the management.

\section{Treatment}

A multidisciplinary team that includes at least a radiologist, an oncological surgeon, a radiotherapist, a medical oncologist, and a pathologist establishes the therapeutic strategy and the sequence of therapeutic stages in multiple breast carcinomas. When confronted with the presence of a multiple breast carcinoma, clinicians encounter several difficulties concerning surgical management, which involves local/ regional treatment leading to a wide excision of breast tissue. There is no standard method in the surgical management and treatment of multiple carcinoma. However, lately, a more conservative approach has been adopted consisting of subtotal mastectomy/ lumpectomy /wide sectorectomy and management of the axilla (sentinel lymph node biopsy in order to prevent total axillary lymph node dissection when the sentinel lymph node is negative)(60). Also, since these cases are associated to a higher extent with axillary lymph node metastases (in which case chemotherapy is recommended), they would benefit more from adjuvant chemotherapy than patients with unifocal tumors.

\section{Prognosis}

Multifocality is not listed among the "traditional" prognostic factors (tumor size, histological grade, axillary lymph node status) or among the second generation ones (ER, PR, Ki67 index and HER2 status) in breast carcinoma (5), even if in 2014, a systematic review and a meta-analysis which focused on the effect of multifocality and multicentricity on outcome in early stage breast cancer and in which 22 studies were evaluated (with a total of 67,500 women included) revealed that in univariable analyses, multifocality was associated with worse disease specific survival and worse local rate recurrence at 10 years. Also, in multivariable analyses, multifocality was associated with significantly worse overall survival (61). However, studies regarding the prognostic significance of multiple foci in breast carcinomas are contradictory and the differences in data could be caused by many factors, such as: case inclusion criteria, variations in the definitions used, different statistical analysis methods and different interpretations $(4,11,13$, 20, 22, 26, 27, 62- 68). (Table 3)

We aimed to analyze survival in multiple breast carcinomas compared with unifocal ones, in order to assess the impact of multi-focality on prognosis. We conducted a retrospective study that included 460 consecutive cases of breast carcinomas admitted to the Pathology Department Tîrgu Mureş between 2002-2006. Out of these, $69(15 \%)$ cases were multiple carcinomas, and $391(85 \%)$ cases were unifocal carcinomas. In our study, multifocality was associated with a lower general survival at 5 years and at 10 years, yielding a higher mortality rate and a lower median survival rate, but did not constitute an independent prognostic factor in multivariate analysis (69).

\section{Conclusions}

Firstly, we have demonstrated that the incidence of multiple breast carcinomas in Romania is similar to the one reported internationally if the radiological-pathological sampling method is applied and a good correlation among data and the members of the multidisciplinary 
Table 3. Studies regarding the prognostic significance of multiple foci in breast carcinoma (MFMC carcinoma vs. UF carcinoma)

\begin{tabular}{ll}
\hline Authors & Survival indicators \\
\hline Worse prognosis & \\
\hline Egan,1982 (20) & Mortality $\uparrow$ \\
\hline Dabakuyo,2008 (63) & Mortality $\uparrow$ \\
& 5 and 10-year survival $\downarrow$ \\
\hline Yerushalmi,2009 (4) & Survival rate slightly $\downarrow$ \\
\hline Boyages,2010 (62) & Mortality rate $\uparrow$ \\
& 5 and 10-year survival $\downarrow$ \\
\hline Weissenbacher,2010 (68) & Mean survival $\uparrow$ \\
& $\uparrow$ Local recurrence rate \\
& $\uparrow$ Rate of distant metastases \\
\hline Tot, 2011 (67) & $\uparrow$ Risk of death due to breast \\
& carcinoma \\
\hline Ustaalioglu, 2012 (24) & $\downarrow$ Disease free survival \\
\hline Pekar, 2013 (53) & $\downarrow$ Breast Cancer Specific Survival \\
\hline No influence on prognosis & \\
(no statistically significant differences between compared groups) \\
\hline Vlastos, 2000 (11) & Breast Cancer Specific Survival at \\
& 10 years \\
& Disease-Free Survival \\
\hline Middleton, 2002 (22) & Disease-Free Survival at 5 and 10 \\
\hline Oh, 2006 (65) & years \\
\hline Litton, 2007 (64) & Overall Survival at 5 years \\
\hline Joergensen, 2008 (13) & Overall Survival, Relapse-Free \\
\hline Reabioglu, 2009 (27) & Survival \\
\hline Lynch, 2012 (66) & Overall Survival \\
\hline & Disease-Free Survival at 5 years \\
\hline & Overall Survival, Progression Free \\
& Survival \\
\hline & Relapse-Free Survival, Breast \\
& Cancer Specific Survival - worse \\
& prognosis at 5 years (only in UVA, \\
& not in MVA - other factors are \\
& associated with $\downarrow$ survival rates) \\
\hline
\end{tabular}

team is met in every case.

Secondly, we have demonstrated that there is a morphological and molecular heterogeneity among multiple tumor foci and this should have an impact on management. So, each focus of the multiple breast carcinoma matters and we strongly recommend that each focus should be investigated and reported, and therapeutical decisions should only be made by taking into the consideration tumor foci heterogeneity, even if the decision regarding the treatment in the presence of multiple tumors is still internationally debated.
Thirdly, we have demonstrated that both multiple and unifocal breast carcinomas are not stable during the metastatic process and even homogeneous multiple foci can change morphology and molecular profile when reaching the axilla, so we recommend markers to be evaluated and the molecular profile to be done on the axillary lymph node metastases also.

Finally, although multicentricity does not constitute an independent prognostic factor in multivariate analysis, multiple breast carcinomas have a worse prognosis than unifocal ones and this should be taken into consideration when establishing the treatment.

\section{Acknowledgement}

We thank Adrian Năznean from the Foreign Language Department, University of Medicine and Pharmacy of Tîrgu Mureş for carefully correcting this manuscript.

\section{References}

1. Ferlay J, Shin HR, Bray F, Forman D, Mathers C, Parkin DM, eds GLOBOCAN 2008 v 1.2, Cancer incidence and mortality worldwide: IARC CancerBase No. 10, Lyon, France: International Agency for Research on Cancer (http://globocan.iarc.fr).

2. Anghel R, Minea L, Dediu M, Bacinschi X, Eniu A, Eniu D, Miron L, Aldean B: Ghidul de management al cancerului mamar; Monitorul Oficial, Partea I, Nr. 608 bis, septembrie 2009, Anexa 9.

3. Katz A, Strom EA, Buchholz TA, Theriault R, Singletary SE, McNeese MD. The influence of pathologic tumor characteristics on locoregional recurrence rates following mastectomy. Int J Radiat Oncol Biol Phys. 2001;50(3):735-42.

4. Yerushalmi R, Kennecke H, Woods R, Olivotto IA, Speers C, Gelmon KA. Does multicentric/multifocal breast cancer differ from unifocal breast cancer? An analysis of survival and contralateral breast cancer incidence. Breast Cancer Res Treat. 2009;117(2):365-70. doi: 10.1007/ s10549-008-0265-1. Epub 2008 Dec 11.

5. Tot T. The role of large-format histopathology in assessing subgross morphological prognostic parameters: a single institution report of 1000 consecutive breast cancer cases. Int J Breast Cancer. 2012; 2012:395415. doi: 10.1155/2012/395415. Epub 2012 Oct 21.

6. Boros M, Stolnicu S. Heterogeneity in multiple breast carcinomas: therapeutic and prognostic implications. Tirgu Mures: University Press; 2014.

7. Hunter J. Lectures on the Principles of Surgery. Philadelphia: Haswell, Barrington and Haswell. 1839; Of Cancer: 377-78.

8. Lagios MD. Multicentricity of breast carcinoma demonstrated by routine correlated serial subgross and radiographic examination. Cancer. 1977 Oct;40(4):1726-34.

9. Holland R, Veling SH, Mravunac M, Hendriks JH. Histologic multifocality of Tis, T1-2 breast carcinomas. Implications for clinical trials of breast-conserving surgery. Cancer. 1985;56(5):979-90.

10. Sarnelli R, Squartini F. Multicentricity in breast cancer: a sub- 
macroscopic study. Pathol Annu. 1986;21 Pt 1:143-58.

11. Vlastos G, Rubio IT, Mirza NQ, Newman LA, Aurora R, Alderfer J, et al. Impact of multicentricity on clinical outcome in patients with T1-2, N0-1, M0 breast cancer. Ann Surg Oncol. 2000;7(8):581-7.

12. Fish EB, Chapman JA, Link MA. Assessment of tumor size for multifocal primary breast cancer. Ann Surg Oncol. 1998;5(5):442-6.

13. Joergensen LE, Gunnarsdottir KA, Lanng C, Moeller S, Rasmussen BB. Multifocality as a prognostic factor in breast cancer patients registered in Danish Breast Cancer Cooperative Group (DBCG) 1996-2001. Breast. 2008;17(6):587-91. doi: 10.1016/j.breast. 2008.06.004. Epub 2008 Aug 8.

14. Pedersen L, Gunnarsdottir KA, Rasmussen BB, Moeller S, Lanng C. The prognostic influence of multifocality in breast cancer patients. Breast. 2004;13(3):188-93.

15. Rezo A, Rodins K, Davis AJ, Shadbolt B, Zhang Y, Huynf F, et al. Assessment of tumor size and its relationship to nodal involvement in multifocal and multicentric breast cancer. J Clin Oncol. 2007;25 (18 Suppl):10602.

16. Stolnicu S, Mocan S, Radulescu D. Diagnosticul morfologic al leziunilor mamare. Targu Mures: University Press; 2005. XII: 193- 217.

17. Tavassoli F, Devilee P. World Health Organization Classification of Tumors. Pathology and Genetics of Tumours of the Breast and Female Genital Organs. Lyon:IARC Press; 2003. p. 10- 11.

18. Morgenstern L, Kaufman PA, Friedman NB. The case against tylectomy for carcinoma of the breast. The factor of multicentricity. Am J Surg. 1975;130(2):251-8.

19. Schwartz GF, Patchefsky AS, Feig SA, Shaber GS, Schwartz AB. Clinically occult breast cancer. Multicentricity and implications for treatment. Ann Surg. 1980 Jan;191(1):8-12.

20. Egan RL. Multicentric breast carcinomas: clinical-radiographicpathologic whole organ studies and 10-year survival. Cancer. 1982; 49(6):1123-30.

21. Qualheim RE, Gall EA. Breast carcinoma with multiple sites of origin. Cancer. 1957;10(3):460-8.

22. Middleton LP, Vlastos G, Mirza NQ, Eva S, Sahin AA. Multicentric mammary carcinoma: evidence of monoclonal proliferation. Cancer. 2002;94(7):1910-6.

23. Luttges JL, Kalbfleish H, Prinz P. Nipple involvement and multicentricity in breast cancer. A study on whole organ sections. J Cancer Res Clin Oncol. 1987;113(5):481-7.

24. Ustaalioglu BO, Bilici A, Kefeli U, Seker M, Oncel M, Gezen C, et al. The importance of multifocal/multicentric tumor on the diseasefree survival of breast cancer patients: single center experience. Am J Clin Oncol. 2012;35(6):580-6.

25. Jain S, Rezo A, Shadbolt B, Dahlstrom JE. Synchronous multiple ipsilateral breast cancers: implications for patient management. Pathology. 2009;41(1):57-67. doi: 10.1080/00313020802563502.

26. Rezo A, Dahlstrom J, Shadbolt B, Rodins K, Zhang Y, Davis AJ; ACT \& SENSW BCTG. Tumor size and survival in multicentric and multifocal breast cancer. Breast. 2011;20(3):259-63. doi: 10.1016/ j.breast.2011.01.005. Epub 2011 Feb 15.

27. Cabioglu N, Ozmen V, Kaya H, Tuzlali S, Igci A, Muslumanoglu M, et al. Increased lymph node positivity in multifocal and multicentric breast cancer. J Am Coll Surg. 2009;208(1):67-74. doi: 10.1016/ j.jamcollsurg.2008.09.001. Epub 2008 Oct 31.

28. Choi Y, Kim EJ, Seol H, Lee HE, Jang MJ, Kim SM, et al. The hormone receptor, human epidermal growth factor receptor 2, and molecular subtype status of individual tumor foci in multifocal/ multicentric invasive ductal carcinoma of breast. Hum Pathol. 2012;43(1):48-55. doi: 10.1016/j.humpath.2010.08.026. Epub 2011 Jul 5

29. Tot T. Clinical relevance of the distribution of the lesions in 500 consecutive breast cancer cases documented in large-format histologic sections. Cancer. 2007;110(11):2551-60.

30. Dawson PJ, Baekey PA, Clark RA. Mechanisms of multifocal breast cancer: an immunocytochemical study. Hum Pathol. 1995;26(9): 965-9.
31. Fischer U, Vosshenrich R, Probst A, Burchhardt H, Grabbe E. Preoperative MR-mammography in diagnosed breast carcinoma. Useful information or useless extravangance? Rofo. 1994;161(4): 300-6. German

32. Gupta $D$, Nath M, Layfield LJ. Utility of four-quadrant random sections in mastectomy specimens. Breast J. 2003;9(4):307-11.

33. Say CC, Donegan WL. Invasive carcinoma of the breast: prognostic significance of tumor size and involved axillary lymph nodes. Cancer. 1974;34(2):468-71

34. Huo L. A practical approach to grossing breast specimens. Ann Diagn Pathol. 2011;15(4):291-301. doi: 10.1016/j.anndiagpath.2011.03.005.

35. Edge SB, Byrd DR, Compton CC et al: American Joint Committee on Cancer (AJCC) Cancer Staging Manual, Breast, Part VII, Seventh edition. New York: Springer; 2010. p. 347-76.

36. Lakhani S, Ellis IO, Schnitt SJ et al: WHO Classification of Tumours of the Breast. Lyon: IARC Press; 2012. p. 10-71.

37. Boros M, Moldovan C, Molnar Varlam C, Podoleanu C, Georgescu $\mathrm{R}$, Stolnicu $\mathrm{S}$. Which is the best method to measure the size in multiple breast carcinoma in correlation with impact on prognosis? A retrospective study of 418 cases. Int J Clin Exp Med 2016;9(2): 3489-96.

38. Andea AA, Wallis T, Newman LA, Bouwman D, Dey J, Visscher DW. Pathologic analysis of tumor size and lymph node status in multifocal/multicentric breast carcinoma. Cancer. 2002:94(5):1383-90.

39. Moutafoff C, Coutant C, Bézu C, Antoine M, Werkoff G, Benbara A, Uet al. Prognostic and predictive factors in multifocal breast carcinoma. Gynecol Obstet Fertil. 2011;39(7-8):425-32. doi: 10.1016/j.gyobfe. 2011.05.001. Epub 2011 Jul 12. French

40. Eeles R, Knee G, Jhavar S, Mangion J, Ebbs S, Gui G, et al. Multicentric breast cancer: clonality and prognostic studies. Breast Cancer Res Treat. 2011;129(3):703-16. doi: 10.1007/s10549-0101230-3. Epub 2010 Nov 16.

41. Perry N, Broeders M, De Wolf C et al: European Guidelines for Quality Assurance in Breast Cancer Screening and Diagnosis, fourth edition. Office for Official Publications of the European Communities, Luxemburg; 2006. p. 219-313.

42. Lester SC, Bose S, Chen YY, Connolly JL, de Baca ME, Fitzgibbons PL, et al. Members of the Cancer Committee, College of American Pathologists. Protocol for the examination of specimens from patients with invasive carcinoma of the breast. Arch Pathol Lab Med. 2009;133(10):1515-38. doi: 10.1043/1543-2165-133.10.1515.

43. Senkus E, Kyriakides S, Penault-Liorca F, Poortmans P, Thompson A, Zackrisson S, et al. Primary breast cancer: ESMO Clinical Practice Guidelines for diagnosis, treatment and follow-up. Annals of Oncology. 2013:24 (Supplement 6):vi7- vi23.

44. Aebi S, Davidson T, Gruber $\mathrm{G}$ et al. Primary breast cancer: ESMO Clinical Practice. Guidelines for diagnosis, treatment and follow-up. Ann Oncol. 2011; 22 (Suppl 6): vi12- vi24.

45. Goldhirsch A, Winer EP, Coates AS, Gelber RD, Piccart-Gebhart M, Thürlimann B, et al. Personalizing the treatment of women with early breast cancer: highlights of the St Gallen International Expert Consensus on the Primary Therapy of Early Breast Cancer 2013. Ann Oncol. 2013;24(9):2206-23.

46. Goldhirsch A, Wood WC, Coates AS, Gelber RD, Thürlimann B, Senn $\mathrm{HJ}$; Panel members. Strategies for subtypes--dealing with the diversity of breast cancer: highlights of the St. Gallen International Expert Consensus on the Primary Therapy of Early Breast Cancer 2011. Ann Oncol. 2011;22(8):1736-47. doi: 10.1093/annonc/mdr304. Epub 2011 Jun 27.

47. Boros M, Marian C, Moldovan C, Stolnicu S. Morphological heterogeneity of the simultaneous ipsilateral invasive tumor foci in breast carcinoma: a retrospective study of 418 cases of carcinomas. Pathol Res Pract. 2012;208(10):604-9. doi: 10.1016/j.prp.2012.07. 005. Epub 2012 Aug 24.

48. Carlson RW, Allred DC, Anderson BO, Burstein HJ, Carter WB, Edge $\mathrm{SB}$, et al. Invasive breast cancer: clinical practice guidelines in oncology. J Natl Compr Canc Netw. 2011;9(2):136-222. 
49. Buggi F, Folli S, Curcio A, Casadei-Giunchi D, Rocca A, Pietri E, et al. Multicentric/multifocal breast cancer with a single histotype: is the biological characterization of all individual foci justified? Ann Oncol. 2012;23(8):2042-6. doi: 10.1093/annonc/mdr570. Epub 2012 Jan 4.

50. Garimella V, Long ED, O'Kane SL, Drew PJ, Cawkwell L. Oestrogen and progesterone receptor status of individual foci in multifocal invasive ductal breast cancer. Acta Oncol. 2007;46(2):204-7.

51. Pekmezci M, Szpaderska A, Osipo C, Erşahin C. Evaluation of biomarkers in multifocal/multicentric invasive breast carcinomas. Int J Surg Pathol. 2013;21(2):126-32. doi: 10.1177/1066896912467370. Epub 2012 Nov 30

52. Boros M, llyes A, Nechifor Boila A, Moldovan C, Eniu A, Stolnicu S Morphologic and molecular subtype status of individual tumor foci in multiple breast carcinoma. A study of 155 cases with analysis of 463 tumor foci. Hum Pathol. 2014;45(2):409-16. doi: 10.1016/ j.humpath.2013.10.006. Epub 2013 Oct 18.

53. Pekar G, Gere M, Tarjan M, Hellberg D, Tot T. Molecular phenotype of the foci in multifocal invasive breast carcinomas: intertumoral heterogeneity is related to shorter survival and may influence the choice of therapy. Cancer. 2014;120(1):26-34. doi: 10.1002/cncr.28375. Epub 2013 Oct 11.

54. Boros M, Podoleanu C, Georgescu R, Moldovan C, Molnar C, Stolnicu S. Multifocal/multicentric breast carcinomas showing intertumoral heterogeneity: a comparison of histological tumor type and Nottingham histological grade of primary tumour and lymph node metastasis. Pol J Pathol. 2015;66(2):125-32.

55. Aitken SJ, Thomas JS, Langdon SP, Harrison DJ, Faratian D. Quantitative analysis of changes in ER, PR and HER2 expression in primary breast cancer and paired nodal metastases. Ann Oncol. 2010;21(6):1254-61. doi: 10.1093/annonc/mdp427. Epub 2009 Oct 25.

56. Ataseven B, Gologan D, Gunesch A, Kehl V, Hoegel B, Beer M, et al. HER2/neu, Topoisomerase 2a, estrogen and progesterone receptors: discordance between primary breast cancer and metastatic axillary lymph node in expression and amplification characteristics. Breast Care (Basel). 2012;7(6):465-70. doi: 10.1159/000345467.

57. Jensen JD, Knoop A, Ewertz M, Laenkholm AV. ER, HER2, and TOP2A expression in primary tumor, synchronous axillary nodes, and asynchronous metastases in breast cancer. Breast Cancer Res Treat. 2012; 132(2):511-21. doi: 10.1007/s10549-011-1610-3 Epub 2011 Jun 11.

58. Nedergaard L, Haerslev T, Jacobsen GK. Immunohistochemical study of estrogen receptors in primary breast carcinomas and their lymph node metastases including comparison of two monoclonal antibodies. APMIS. 1995;103(1):20-4.

59. Georgescu R, Boros M, Moncea D, Bauer O, Coros MF, Oprea A, et al.
Discordance Rate in Estrogen Receptor, Progesterone Receptor, HER2 Status, and Ki67 Index Between Primary Unifocal and Multiple Homogenous Breast Carcinomas and Synchronous Axillary Lymph Node Metastases Have an Impact on Therapeutic Decision. Appl Immunohistochem Mol Morphol. 2017 Jan 17. doi: 10.1097/ PAI.0000000000000483. [Epub ahead of print]

60. Gentilini 0 , Veronesi P, Botteri E, Soggiu F, Trifirò G, Lissidini G, et al. Sentinel lymph node biopsy in multicentric breast cancer: five-year results in a large series from a single institution. Ann Surg Oncol. 2011;18(10):2879-84. doi: 10.1245/s10434-011-1694-3.

61. Vera-Badillo FE, Napoleone M, Ocana A, Templeton AJ, Seruga B, Al-Mubarak M, et al. Effect of multifocality and multicentricity on outcome in early stage breast cancer: a systematic review and meta-analysis. Breast Cancer Res Treat. 2014;146(2):235-44. doi: 10.1007/s10549-014-3018-3. Epub 2014 Jun 14.

62. Boyages J1, Jayasinghe UW, Coombs N. Multifocal breast cancer and survival: each focus does matter particularly for larger tumors. Eur $\mathrm{J}$ Cancer. 2010;46(11):1990-6. doi: 10.1016/j.ejca.2010.03.003.

63. Dabakuyo TS, Bonnetain F, Roignot P, Poillot ML, Chaplain G, Altwegg $T$, et al. Population-based study of breast cancer survival in Cote d'Or (France): prognostic factors and relative survival. Ann Oncol. 2008;19(2):276-83. Epub 2007 Oct 24.

64. Litton JK, Eralp Y, Gonzalez-Angulo AM, Broglio K, Uyei A, Hortobagyi GN, et al. Multifocal breast cancer in women $<$ or $=35$ years old. Cancer. 2007;110(7):1445-50.

65. Oh JL, Dryden MJ, Woodward WA, Yu TK, Tereffe W, Strom EA, et al. Locoregional control of clinically diagnosed multifocal or multicentric breast cancer after neoadjuvant chemotherapy and locoregional therapy. J Clin Oncol. 2006;24(31):4971-5.

66. Lynch SP, Lei X, Chavez-MacGregor M, Hsu L, Meric-Bernstam F, Buchholz TA, et al. Multifocality and multicentricity in breast cancer and survival outcomes. Ann Oncol. 2012;23(12):3063-9. doi: 10.1093/annonc/mds136. Epub 2012 Jul 9.

67. Tot T, Gere M, Pekár G, Tarján M, Hofmeyer S, Hellberg D, et al. Breast cancer multifocality, disease extent, and survival. Hum Pathol. 2011;42(11):1761-9. doi: 10.1016/j.humpath.2011.02.002.

68. Weissenbacher TM, Zschage M, Janni W, Jeschke U, Dimpfl T, Mayr D, et al. Multicentric and multifocal versus unifocal breast cancer: is the tumor- node-metastasis classification justified? Breast Cancer Res Treat. 2010;122(1):27-34. doi: 10.1007/s10549010-0917-9. Epub 2010 May 8.

69. Boros M, Voidazan S, Moldovan C, Georgescu R, Toganel C, Moncea $\mathrm{D}$, et al. Clinical implications of multifocality as a prognostic factor in breast carcinoma - a multivariate analysis study comprising 460 cases. Int J Clin Exp Med. 2015;8(6):9839-46. eCollection 2015. 